\title{
Fasten Your Seat Belt
}

\section{Dear Reader,}

Do you know how many metres of safety belt there are in a car? Opel has measured the belts in its current five-seater Astra model and their total length is exactly $15.9 \mathrm{~m}$. That's a lot of belt. It's much longer than a penalty kick in the European Football Championships, which are just now coming to an end, and approximately the equivalent of the width of two football goals put side-by-side.

It was in 1959 that the Swedish engineer Nils Ivar Bohlin, who worked for Volvo, patented the three-point safety belt in Germany. During the 1960s, the new belts gradually began to replace the unsafe and uncomfortable lap belts in use at the time. The three-point belt became a mandatory feature of new cars in 1974 and the legal requirement to wear it was introduced in 1976, exactly 40 years ago. These two developments had little impact on the accident statistics until the introduction of a penalty charge of 40 deutschmarks increased the proportion of car occupants wearing seat belts from 58 to $92 \%$.

Nowadays, the seat belt is no longer the only safety system, but still by far the most important. It has been joined by airbags, electronic stability control systems and assistance systems, such as adaptive cruise control and traffic jam assist, based on camera and radar technology. This means that we can now talk about integrated safety by which we mean a combination of active and passive safety measures. There is still a need to improve vehicle and road safety in order to reverse the rise in the number of deaths on German roads (0.9 \% in 2014 and $2.9 \%$ in 2015). The intelligent interaction of the seat belt, airbag, brakes and warning and assistance systems now plays an even more important role in ensuring that we are safe on the roads.
Given the benefits of these systems, it is hard to believe the following headline, which appeared in a press release from the German Road Safety Council (DVR) in May 2016: "Women are less likely to opt for safety”. This statement was the result of a survey carried out as part of the "Best Passenger" campaign run by the DVR and its partners. The interviewers noticed that only $22 \%$ of women made use of the safety benefits of driver assistance systems, while the proportion of men doing so was at least $30 \%$. Apparently they have not yet realised that these systems can save lives.

Hopefully the numbers will soon reach the same $90 \%$ level as that of seat belt wearers. So please "fasten your seat belt" and enjoy reading the articles about our cover theme of safety.

Best wishes,

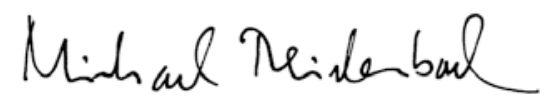

Dipl.-Ing. Michael Reichenbach Deputy Editor in Chief

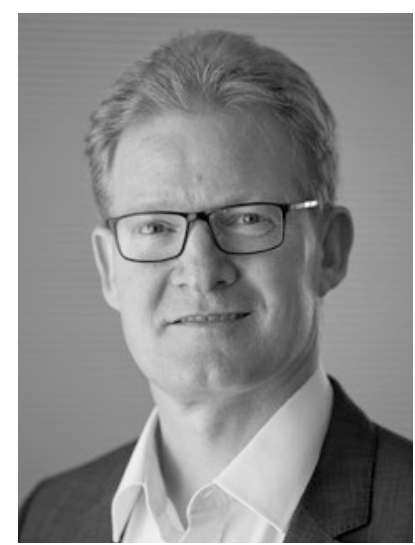

